\title{
Towards People-Private-Public Partnerships: An integrated COMMunity ENGAGEMENT MODEL FOR CAPTURING ENERGY ACCESS NEEDS
}

\author{
Bothwell Batidzirai $^{\mathrm{a}}$, Philipp A. Trotter ${ }^{\mathrm{b}, \mathrm{c}}$, Aoife Brophy ${ }^{\mathrm{b}, \mathrm{d}}$, Susann Stritzke ${ }^{\mathrm{b}}$, Alfred Moyo ${ }^{\mathrm{a}}$, Peter \\ Twesigye $^{\mathrm{e}}$, Akaraseth Puranasamriddhi $^{\mathrm{b}}$, Amos Madhlopa ${ }^{\mathrm{a}}$ \\ ${ }^{a}$ Energy Research Centre, University of Cape Town, South Africa \\ ${ }^{\mathrm{b}}$ Smith School of Enterprise and the Environment, University of Oxford, UK \\ ${ }^{c}$ Chair of Operations Management, RWTH Aachen University, Germany \\ ${ }^{\mathrm{d}}$ Saïd Business School, University of Oxford, UK \\ ${ }^{\mathrm{e}}$ Graduate School of Business, University of Cape Town, South Africa
}

\begin{abstract}
It is widely accepted that community engagement is vital for achieving sustainable development outcomes. While governments in several low-income countries have introduced community engagement for their electrification initiatives, the adequacy of traditional top-down approaches to capture community needs has been contested. In this paper, we holistically assess the barriers to needscentric community engagement. Based on a community survey with 1.016 participants and 54 semistructured interviews with government institutions and energy businesses in Uganda and Zambia, we unpack the relationships between communities and the public sector, and between communities and energy companies to interrogate the realities of community engagement in rural electrification. We find considerable gaps between community preferences for needs-centric engagement and how public and private sectors are currently engaging. Key institutional barriers for needs-centric community engagement are vertical and horizontal disconnections within the public sector as well as challenging and ineffective sharing of crucial information. For energy companies the main obstacle is the limited value attributed to a deep understanding of community needs. Based on our results, we develop an integrated model for community engagement focused on capturing energy needs. The model combines top-down and bottom-up engagement approaches where public institutions play a catalytic role in setting a flexible enabling environment for energy companies to establish deep connections with local communities, and where communities are given a platform to define and communicate immediate and long-term needs through context-specific means.
\end{abstract}

Keywords: Community engagement, sub-Saharan Africa, renewable energy, rural electrification, energy access

\section{INTRODUCTION}

Access to quality and affordable electricity can function as a key enabler for economic development in developing regions such as Africa [1], but the rate of access to electricity in sub-Saharan Africa (SSA) is low, currently standing at only $32 \%$ [2]. Furthermore, the degree of urban-rural electrification inequality, i.e. the difference between urban and rural electricity access levels, is greater in SSA than it

\footnotetext{
${ }^{1}$ E-mail address: b.batidzirai@gmail.com

Full address: Energy Research Centre, University of Cape Town, Bag X3 Rondebosch 7700, Cape Town, South Africa
} 
is anywhere else in the world [3-5]. About 70\% of the urban population in SSA has access to electricity compared to about $25 \%$ in corresponding rural areas [6], figures that are significantly lower than the global average rate of $87 \%$ and that of other developing regions such as Asia and Latin America where electrification is at least $85 \%[3,5,7]$. It is therefore not surprising that many SSA governments have embarked on rural electrification programmes to accelerate electricity access. Nevertheless, there has been slow progress in raising the rates of access to electricity in the region. Given the limitations within the public sector, governments are increasingly relying on the private sector to deliver energy to rural communities [8]. But even where progress has been made, access has often failed to deliver more than basic energy needs for communities [9-12].

The paradigm for modern energy access and development has shifted considerably in the last few decades from being predominantly aid-based in the 1970s and 1980s, to a focus on market creation in the 1990s and early 2000s, to an integrated, sustainable development paradigm since the late 2010s $[13,14]$. In order for energy access to enable sustainable development, however, the public sector, the private sector and communities need to work together in new ways [13]. However, many attempts to engage with local communities in low-income countries on electrification have been marred by challenges. Global experiences have shown that development projects have stalled due to community opposition based on concerns over project impacts, land ownership or other related issues [15-17]. Best practices suggest that community engagement should be systematically integrated into development activities to lower project risks, avoid disputes and grievances as well as avoid cost and time overruns during implementation [18-20]. Yet, even where community engagement has been prevalent, outcomes have often been unsatisfactory. A top-down approach to community engagement has dominated where the visions of those planning and delivering projects are developed separately from local actors. Policy makers tend to focus on informing communities rather than on involving communities in planning or delivery [21], which has led to a lack of meaningful participatory decision-making [22]. Critically, such top-down community engagement often fails to capture the actual needs of the communities or local contextual dynamics [23], a problem that spans both the public and private sectors [24,25]. This shortcoming has become more salient as debates about the purpose of increasing energy access have been shifting towards user-centric perspectives which require integrative approaches [26]. Both the wider literature on community engagement [27] and the energy access literature specifically [22] argue that addressing the people-private-public nexus and understanding the barriers to meaningful, needs-centric community engagement require new research.

In this paper, we use the experiences in rural Uganda and Zambia to analyse the relationships between communities and the public sector as well as the private sector to explore two main questions. First, what are the barriers to needs-centric community engagement for rural electrification? And second, which guiding principles enable communities, public institutions and energy businesses to focus on end-user needs? Critically, we capture, analyse and integrate the distinct perspectives of communities, of the public sector and of the private sector separately and in two countries. Using household surveys 
and semi-structured interviews to understand each of these actors approaches to community engagement, as well as their mutual relationships, we aim to move beyond a top-down analytical approach to community engagement. Based on our results, we develop an integrated community engagement model for needs-centric energy access where the people, the private sector and the public sector are closely interlinked.

\section{BACKGROUND}

\subsection{Community engagement by the public sector for rural electrification}

Community engagement by the public sector often involves a strategic, medium to long-term focus of policy strategy and instrument design. From the perspective of the public sector, the development of policies for rural electrification is complex and becoming even more so as policymakers realise that electrification and energy access do not automatically lead to development outcomes [28]. There are two main considerations for the public sector: The first is to understand the purpose for engagement, and the second is to decide on the means of engagement.

Firstly, understanding and defining the purpose for engagement is critical for the public sector in order to connect rural electrification with the sustainable development agenda [25,29,30]. Stirling [31] identified three predominant rationales for community engagement - normative, instrumental and substantive. From a normative perspective, participation is just the right thing to do. From an instrumental perspective, it is a better way to achieve particular outcomes. From a substantive perspective, it leads to better outcomes overall. Normative and substantive rationales are important in guiding the purpose of community engagement for sustainable development as they enable a redefinition of outcomes [32]. Despite the widespread acknowledgement of the importance of involving communities more substantively in the definition of outcomes and in their empowerment, there are few examples in the rural energy context where community engagement of this type has been applied. A recent review of rural energy planning, for example, found that only a third of projects studied across a variety of contexts had some level of community engagement. Of these projects, the purpose of engagement was to gather information from the communities rather than to involve them directly in any types of strategic policy-making [13]. This issue is mirrored in energy contexts beyond electrification in low-income countries such as fossil fuel extraction where national interests can thwart community initiatives towards meaningful community engagement [33]. Electrification projects also often involve a complex constellation of actors including NGOs and donors. These actors may have different project objectives and priorities from the public sector. The diversity of objectives, for example environmental, health and education can make it difficult to assess whether projects have been successful. This diversity can also sometimes lead to a focus for example by funders on outcomes that are not aligned with end 
user needs, expectations and values [34], making it even more critical for the public sector to be clear about the purpose for engaging with communities.

Secondly, going beyond gathering information from communities requires careful consideration of the means of engagement. The means can range from informing and consulting to involving and collaborating with communities $[35,36]$. These different means of engagement are distinguished by the flow of information between actors, where the directions and intensity vary. In the simplest form, stakeholders are merely informed, for example via fact sheets or at village meetings. Collaboration or even empowerment where final decision-making is in the hands of the public are focused not only on incorporating stakeholder views in the development of policies and programmes but also on enhancing ownership (e.g. see [37,38]). The majority of rural energy projects have been based on information or consulting, rather than involving, collaborating or empowering [13]. This is despite the fact that assessments of existing projects across countries have clearly shown that involving communities early and in an on-going manner enables more successful project outcomes [32,34,39]. There have been several recent examples of deeper engagement. In Guyana, for example, representatives from remote communities collaborated in the design process for the electrification plans through a combination of individual meetings and workshops [40]. In Ecuador, one of the most successful projects for off-grid PV systems was developed in collaboration with an electrification committee composed of representatives from different parts of the community. Despite the success of the model, it has not been adopted widely in the rest of the country or region [41]. Even where communities are more deeply involved, the link to empowerment is not so straightforward and requires close attention [42]. Existing participatory methodologies often fail to change and challenge the bureaucratic and centralised administrative structures that control decision-making and resource allocation. The way in which participation is designed often fails to adequately take the views of the poor and marginalised into account and can in many cases serve to underscore existing power relations [43].

In summary, existing policy and project planning led by the public sector have seen limited ambition in terms of the purpose of community engagement and mostly have a focus on informing and consulting communities. Where there have been examples of deep engagement with communities, there are significant barriers to the widespread adoption of these practices.

\subsection{Community engagement by the private sector for rural electrification}

Expectations for energy businesses to engage with communities in the context of energy access have been growing [13]. Many low-income countries rely increasingly on the private sector for implementing rural electrification [44,45]. Businesses have sustained and direct end-user interactions [46]. They therefore play a key role in immediate community engagement usually covering short-term timeframes [47]. Recent research on rural energy projects across geographies point to two main opportunities for energy businesses to improve the ways in which they engage with communities. 
The first opportunity is to improve understanding of current energy needs. The project developers and energy providers who operate and maintain solar home systems and mini-grids for example, and related companies who provide services such as financing for appliances, interact with users in various ways $[8,47]$. Developers for instance physically assess project sites, bringing them into close contact with communities during planning and implementation phases. Companies who sell energy or energy-related services are connected to users through an ongoing commercial relationship after implementation. And yet the evidence shows that there has not been enough focus on understanding needs either in the implementation of projects [9], in assessing the impact of projects [10] or in their wider socio-cultural implications for communities [48]. This limits the extent to which rural energy projects deliver in ways that will enable communities to thrive. For example, needs beyond basic energy access are often overlooked [9]. If these needs are not incorporated into project planning, the potential for productive use of energy is severely limited [10], contributing to the underlying gap between energy access and development outcomes $[28,49]$. There are different potential approaches to improving understanding of community needs, ranging from top-down engagement where the vision is still driven by project developers but efforts are made to improve awareness of community needs [28]; to ensuring that the project developer remains involved and embedded in the local context after project completion [10]; through to approaches that support partnerships between companies and communities with a shared vision in delivering and operating projects [50].

The second opportunity is to extend the time horizon for thinking about energy needs and by extension engagement with communities. Energy access cannot be solved by individual projects alone. Even if a mini-grid project is successfully implemented taking into account individual and community needs, these needs are likely to adapt over time [51]. Building in flexibility for these needs to change, as opportunities for productive use evolve for instance is challenging and goes beyond the scope of an individual project developer or energy provider. Bowen et al. distinguish between transactional, transitional and transformational community engagement, pointing towards the long-term nature of both transformational engagement types and their payoffs for companies [52]. Networks of partnerships between companies, communities and local governments for instance might be required to support extended engagement with communities to provide lessons for the adaptation or replication of projects for other settings and the translation of these lessons into regional and national policies [53]. Models of long-term partnership between communities and companies for renewable energy projects have received increasing attention particularly in high-income countries. For example Eitan et al., [50] develop a typology of partnerships ranging from knowledge sharing to provision of employment opportunities and leasing models. Developing these partnerships in ways that will benefit communities, however, is difficult in cases where communities are already marginalised, with limited ability to influence decisions due to existing power relations [54,55].

In fact, new models including community energy and collaborative governance arrangements that bring together the private and public sectors with communities at the centre offer a means of combining 
approaches in a more holistic way [34,39]. These models, however, require rethinking the relationships between communities and public institutions, and communities and energy businesses. They also offer opportunities for intermediary organisations such as local NGOs to facilitate partnerships and to coordinate the multiple objectives often embedded in these complex projects [34]. We do not focus on the role of these organisations directly in this paper, but however our findings and discussions can offer insights for intermediaries in supporting community engagement. After discussing our research methods and data (section 3), we examine each of these relationships in turn (section 4.1 and section 4.2, respectively) in order to holistically assess modes, barriers and benefits of engaging with communities.

\section{METHODS AND DATA}

For this study, we collected data via a community survey in rural Uganda and Zambia and interviewed stakeholders on community engagement in both countries' public institutions and the private sector. These data are critical to ensure empirical novelty and relevance of our paper following recommendations in Sovacool et al [56]. They allow us to describe and analyse the barriers for community engagement in rural electrification, and based on the results, develop an integrated model for community engagement which focuses on capturing and implementing community energy needs. We integrate results from our community survey and interviews to understand barriers to community engagement first with the public sector and second with the private sector. Such a mixed method approach has the merit of drawing from both quantitative and qualitative evidence to identify certain effects, and ensure their validity in the chosen context following Sovacool et al [56].

Uganda and Zambia were selected as case studies to enable cross country comparison of community engagement of different countries in the region. The selected countries exhibit similar patterns in electrification processes and outcomes, including, critically, an existing explicit regulatory framework for community engagement in electrification projects in both countries - which thereby allows us to examine the implications of community engagement on rural electrification. Also, while both countries have low electrification rates (below $25 \%$ in 2017 [57]), they both feature a quickly growing off-grid sector driven by public sector ambitions and private sector interest of a largely untapped market, providing an ideal dynamic and multi-actor setting to study community engagement in electrification. Crucially, Uganda and Zambia have contrasting community governance systems, which allows us to analyse and derive insights which transcend beyond some local-level governance differences. Public sector decision making processes show significant sub-national variation in several sub-Saharan African countries [58,59]. The "modern state" in the region has evolved in the post-colonial period, in juxtaposition to a "traditional system" that remains relevant especially in the rural areas where it administratively complements the modern political state and maintains the socio-cultural capital and indigenous social value systems [60]. This bifurcation of governance systems has implications for 
community engagement in public decision making, as the models for participation would differ depending on the degree of integration of the two systems, and the degree of democratisation of the systems. Uganda and Zambia show contrasting community governance systems: While Uganda has developed robust non-traditional political and administrative structures, Zambia has preserved distinct traditional leadership structures which coexist with modern local and regional administrative structures [61]. The formal administrative structures in both countries are organised into decentralised local governments (LGs) units spanning over 134 political districts in Uganda and 118 in Zambia. The Ministries of Local Government in both countries play an oversight supervisory role over the decentralised governments and has an assigned function to support and facilitate local infrastructure development. However, the District level in Uganda entails a further cascade of a political and administrative structure formally recognised and practiced as a Local Council (LCs) system, built up from the grassroots with the lowest unit of a village administered and denoted as LC1, and rising to the highest level of LC5 for the District. In Zambia, the local government structure consists of elected city-, municipal or rural councils, depending on the rural or urban classification of the council district, and these councils are responsible for public services and planning, and also ensures the formal representation of local chiefs in these councils. In both countries, local councils are complemented by political appointees by the President namely Resident District Commissioners (RDC) in Uganda who report directly to the President's Office. In Zambia, the appointee is the District Commissioner (DC) reports directly to the Ministry of Local Government and to one of the 10 Provincial Ministers and their Permanent Secretaries, who are administrative heads of the provinces. The commissioners in both countries are political appointees responsible for Monitoring and Evaluation of government programmes and providing policy input at national level. In Zambia, the 288 Chiefs, as traditional leaders, have significant powers and influence in rural areas with regards to land-ownership and the implementation of infrastructure projects. These chiefs elect 50 representatives amongst them who are formally organised and represented in a central House of Chiefs which is linked to the Ministry of Chiefs and has an advisory role in various policy areas. A recent comprehensive energy governance and policy analysis in both countries, has revealed that energy policy-making processes in both countries are highly centralised, with limited to no local or regional stakeholder engagement [62].

\subsection{Community survey collection}

Using a novel community survey, we collected rural dwellers' views on the state of and perceptions towards community engagement in rural electrification. The survey was designed to explore rural electrification preferences and challenges, as well as to identify opportunities to improve interaction of community members with private energy businesses as well as public sector institutions. Questions included their current and desired degree of involvement and decision-making power in energy access programmes in their communities, how, through whom and via which means they wish to engage with 
energy access issues, how they access information about energy access programmes and options, and for which activities they require modern forms of energy. We furthermore recorded characteristics such as age, education level, income level, gender, connection to electricity, district and sub-national region for each respondent. The questionnaire also captured supporting information such as community priority needs and challenges, experiences and willingness to pay for electricity services. The survey had 106 questions in total, three of which were open, 103 closed. Each enumerator used a hard copy printed questionnaire which they used to capture the responses from the respondents during the interviews.

Our sample included randomly selected rural communities in Central, Eastern, Northern and Western Uganda regions while in Zambia the randomly selected sample communities were located in Eastern and Southern Provinces. The total sample size was 1.016, of these 465 were from Uganda, and 551 from Zambia. We employed stratified random sampling to explore the different categories of community members (targeting households, small business owners and community leaders) and to capture the different experiences and preferences unique to these community subgroups. Also the sampling strategy ensured balance in terms of age, gender, income levels, education levels, as well as electrified vs unelectrified across community members. As shown in Table 1,69\% of the respondents were households, $22 \%$ were small businesses and $6 \%$ were local community leaders.

After drafting the questionnaire, a pre-test was conducted in Katete District in Eastern Zambia, to check consistency and flow of questioning, to check survey duration, and the relevance of questions for the rural context. The feedback from the pilot was used to adjust and finalise the questionnaire. After finalisation, the questionnaire was translated into four languages: Chichewa (for Eastern Zambia), Tonga (for Southern Zambia), Luganda (for Kalangala and Kampala in Uganda) and Acholi (for Gulu in Uganda). Translation was necessary to ensure that the interviews were conducted in each respective local language so as to capture authentic responses. Conducting the interviews in local language ensured that the enumerators would consistently pose the questions uniformly in all cases without translating the English questions according to their own understanding.

Table 1: Distribution of community survey respondents by type of respondent and by country

\begin{tabular}{|l|r|r|r|}
\hline Type of respondent & Uganda & Zambia & Total \\
\hline Households & 278 & 421 & 699 \\
\hline Businesses & 169 & 52 & 221 \\
\hline Community leaders & 10 & 56 & 66 \\
\hline Unspecified & 8 & 22 & 30 \\
\hline Total & 465 & 551 & 1016 \\
\hline
\end{tabular}




\subsection{Semi-structured interviews collection}

We conducted semi-structured interviews with key stakeholders in Uganda and Zambia. Public sector institutions where we conducted interviews in both countries included the Ministry of Energy, the Rural Electrification Agency, the energy regulatory authority, the Ministry of Finance and local government institutions such as the Ministries of Local Government, local council chairpersons and the Zambian House of Chiefs. In terms of interviews with businesses, we focused on energy companies with reach into the communities we had sampled for the survey. These included on-grid and numerous off-grid companies with a product range from small-scale solar home systems sold via standard retail or via pay-as-you-go models, as well as several mini-grid companies. Some of these companies were social enterprises, often referred to as hybrid organisations because of their joint focus on social and economic goals. For the purposes of our analysis with its focus on community engagement, we do not distinguish between these different types of organisations. In total, we conducted semi-structured interviews with 26 public sector stakeholders and with 28 private energy companies in Uganda and Zambia.

A systematic stakeholder-mapping and engagement analysis [62], previous in-country experience and a review of policy-documents [63] revealed that community engagement for energy infrastructure and access projects takes place in both Uganda and Zambia, albeit in a limited, and top-down way. The interviews with the public sector and with companies confirmed this. We thus focused the interviews on finding reasons why community engagement was limited for both groups of stakeholders, asking them about their experience with community engagement, the key barriers for effective communication and project implementation with communities and which factors could enable more in-depth interactions. We also collected primary data on company business models as well as on energy policymaking processes and regulatory frameworks.

The interviews were focused on the degree of stakeholder-interactions between various levels horizontally and vertically as well as the inclusion of certain stakeholders in decision-making processes on these levels. The questionnaires comprised of mostly open questions clustered into separate sections on regulatory frameworks, strategic energy targets and planning, and energy policy-making at both national level and local energy project implementation level, slightly adjusted to each stakeholder group. Around two-thirds of the interviews were captured through a combination of recording and transcription while about a third of the interviews were captured through notes taken by the interviewer, following on requests from interviewees. The interviews were performed as part of a comprehensive energy governance analysis in Uganda and Zambia [62], but the evaluation of the data for this article was focused on the questions and responses with regard to community engagement in the context of energy planning and project implementation. 


\subsection{Data analysis}

\subsubsection{Community survey data analysis}

For the community surveys, after data collection, the surveys were checked for completion, coded and entered into a spreadsheet. Discrepancies in the datasets were identified and corrected. The statistical package Stata ${ }^{\mathrm{TM}}$ and MS Excel pivot tables were used in the analysis. Cross tabulation of key community engagement questions against contextual parameters was employed to reveal any distinct patterns and the effect of the factors related to the different contexts i.e. national, regional, respondent type (household vs business vs community leaders), education, income level, age, gender, electrified vs unelectrified).

\subsubsection{Public sector and private sector interviews data analysis}

For the semis-structured interviews, the data were coded using four main characteristics, namely (1) the level of engagement, i.e. nationally or locally, (2) the type of engagement, applying a distinction between strategic energy planning and the implementation of specific energy projects, (3) the perceived need or willingness for engagement by the stakeholder interviewed, and (4) the individual different challenges and opportunities of community engagement. Coding the data quickly revealed the critical importance of well-designed interactions between the public sector, the private sector and communities for need-centric community engagement. After coding the data, our data analyses focused on identifying common themes within the public sector, and within the private sector respondents in terms of their approach, motivation and ability to engage communities. Comparing these results with the needcentric paradigm of community engagement enabled us to distil several motivational, processual and ability-related shortcomings which have hindered the public and the private sector to understand and capture community needs. After mapping these challenges onto the different interactions between the public sector, the private sector and communities, we combined cross-case and within-case analyses to derive evidence-based interventions aimed at strengthening these interactions between stakeholders.

\section{RESULTS}

\subsection{Community engagement and the public sector}

\subsubsection{The public sector's barriers for needs-centric community engagement}

Our interviews confirmed that the regulatory frameworks in both countries limit community engagement to prescribing operational touch points between private sector developers and communities for mini-grid development and grid extension, but largely leave the details of engagement on the ground to the project developers. This includes the identification and integration of community needs, as well 
as the scope, process and depth of engagement. Interviewees elaborated three such touch points. Firstly, the environmental and social impact assessment is a requirement for rural energy projects in both countries, but does not specify how to engage with communities. Secondly, energy tariff regulations for mini-grids require public community consultations. In Zambia, these regulations are issued by the Energy Regulation Board (ERB) and do not specify how developers should engage with communities. In Uganda, this process is more explicitly defined and requires issuance of prior notices of consultation to local communities in gazetted venues culminating in a one day public hearing workshop or "baraza" in which project developers are required to present their tariff proposals and community benefits, and subsequently receive comments from locals with support of the Electricity Regulatory Authority (ERA). Thirdly, securing land access through applicable Land Acts in both countries usually requires community input. In Zambia 94\% of the land in the country falls under the jurisdiction of the Chiefs. The distinct role of the Chiefs as the local and land-owning authority in rural areas of Zambia largely defines the type of engagement between government representatives or private developers on developing energy projects and thus such projects require theearly involvement and support of the Chief. In Uganda, land is largely privately owned with some portions owned by government. Project developers are required to privately procure land and submit land titles or, if the land is governmentowned, to obtain Land Lease Agreements for submission and verification to the regulator.

Our interviews reveal three main barriers to public sector engagement with communities. Firstly, there is a disconnect between local and national public institutions. Although local levels of government in both countries have access to rural areas and are largely aware of local needs, they are weakly linked to the national level which limits their ability to effectively transmit community demands from local to national level. In Zambia, the role of traditional leaders is a good example that shows the potential for local leaders to support development. As one of the Chiefs explains, "if I don't play a role in development in my chiefdom there will be no development in the chiefdom". The Chiefs are involved in development plans for their chiefdoms including plans for infrastructure and trade, often in collaboration with other partners such as foreign donor organisations as the interviews revealed. With regards to the planning and implementation of infrastructure developments such as electrification projects, the chiefs are typically only informed about the project during the pre-implementation stage. Thus chiefs are seldom consulted by government officials or private developers during the strategic planning of projects. Interviews with developers and government officials revealed that potential project sites are centrally identified and selected, and the local chiefs are then approached for their consent on the selected project sites through an official visit to the chiefs including the presentation of a small courtesy gift. These interactions, which are considered of high importance include a number of customary protocols of respect which have to be observed by government officials as well as private sector developers. On the question of how chiefs or local representatives are involved during energy project planning or implementation, a representative of the Rural Electrification Authority Zambia replied that "Chiefs are informed about the project before implementation. This is the starting point and 
ensures buy-in". These meetings are the gateway to further community involvement and acceptance facilitated by the village headmen who are usually in direct and frequent contact with the chiefs. The communities usually follow the guidance and directions of the chiefs, and opposition to the chiefs' decision is rare, and so is open conflict between communities and their leaders. The chiefs also act as mediators between developers and community representatives in the event of conflict. Chiefs are embedded in their communities and usually do not take decisions isolated from their communities as one chief stated during the semi-structured interviews: “As a chief, I am servant of the people to provide good services and to attract private sector investment. My final goal is to achieve self-sufficiency for the kingdom. Trust of and in the chiefs is the economic engine for economic development of the chiefdom as a board of trustees decides on investment in my chiefdom."

As Chiefs have limited resources to initiate any infrastructural developments or actively reach out to developers, they are unlikely to stop the implementation of such projects. However, they sometimes connect certain demands to their approval such as the connection of their individual 'palaces' if they are located in the proximity of such electrification projects, but overall expressed a high degree of accountability and responsibility for their subjects through the interviews. With regard to the question of "interests" and "accountability" of Chiefs, a senior-Chief responded in an interview that: "there might be self-centred Chiefs but generally Chiefs are accountable to their subjects. Communities need infrastructure and to be developed. Some Chiefs are weak and irresponsible, they look after themselves, take bribes, and get involved in politics. But strong Chiefs look after their kingdom. Chiefs have an advisory function to the government. A chief is not a politician, they are neutral."

About half of the land in rural areas is subject to customary tenure, which also means that this land is not formally registered. The Lands Act of 1995, which is still disputed among chiefs, provides mechanisms to convert land customary owned by traditional leaders into statutory land owned by the government or sold to private investors [64]. This poses potential risks for chiefs should they oppose certain infrastructure developments, their land could be converted and the project implemented without their consent. However, the number of reported cases where chiefs have withheld their consent or refused to allocate land to infrastructure projects is very limited. The only reported cases during the interviews were for some grid connected power generation projects that were not benefitting local rural communities but feeding the national grid.

Similar to their limited strategic involvement at the local level, the chiefs' strategic influence at a national level is minimal. They are consulted through the House of Chiefs by national ministries in some policy areas such as early child marriage or land ownership, but are not consulted or involved in strategic energy planning or decision-making processes. This is mainly due to a lack of awareness at the Ministry of Energy, demonstrating a significant untapped potential in providing direct feedback on actual energy demands and requirements of rural communities. Similarly, in Uganda - which has a more structured decentralised political governance system cascaded to various Local Governments - energy policy development, project planning and implementation is centralised in government ministries and 
highly disconnected from local government. While the District Local Government Chairpersons, Resident District Commissioners and Chief Administrative Officers who head the political and administrative functions are expected to drive development programmes and be the link between communities and central government, these local government institutions are largely not involved in energy policy and planning. Some of these local government institutions are at times informed about energy projects during project implementation phase, but this is usually too late to make meaningful appraisal or incorporation of community needs in the projects. A local government respondent in Uganda noted that "we only get to see REA or Umeme staff during the project implementation phase, often seeking our involvement to engage communities for buy-in, otherwise we are excluded from planning".

Secondly, there is a disconnect between ministries at a national level particularly between the Ministries of Local Government (MLG), the Ministry of Energy (MoE) and the Ministry of Finance. Interviews with MLG in both Uganda and Zambia indicated that this ministry is not significantly involved or consulted by their respective MoE in national energy planning and strategy processes. In addition, the $\mathrm{MoE}$ in both countries does not have sufficient capacity to undertake substantial data collection or energy project evaluation in rural communities. A Resident District Commissioner in Uganda wondered "how do ministries or REA design projects if they don't involve us to give them a fair assessment of the energy needs of the people and communities we lead? We know our communities better than them". In both scenarios above, the nature of interaction between the community, community leaders and responsible government ministries and agencies in usually informally done in a bottom-up approach community members verbally communicate their dissatisfaction with lack of energy services to their district leaders, who then relay the same to the Ministry of Energy. In a few instances, District leaders will formally communicate this in writing or through joint energy sector performance review (JSR) workshops.

Thirdly, where there are connections between local and national levels of government, interviewees point to inefficiencies in the flow of information. While local government institutions are willing to get involved and to share information with national government, there is a lack of dedicated energy-related roles in local governments in both Uganda and Zambia, leading to unclear responsibilities and reporting structures. For instance, in Uganda, the national government points to legal obligations and decrees dealing with stronger involvement of communities in the country. At the district level, however, district chairpersons have voiced frustration by the limited information shared with them from national government about energy projects planned for their districts. Given limited energy access budgets and widely distributed rural communities, such inefficiencies can render effective community engagement highly challenging. 


\subsubsection{Community perspective}

4.1.2.1 Types of community engagement with the public sector

Results from the community survey show that there is a strong disconnect between the state of community engagement and the preferred level of engagement with the public sector by community members in both Uganda and Zambia. In both countries, an average of only $30 \%$ of the respondents are involved in planning or implementation of local electrification initiatives $(\mathrm{N}=157$ in Uganda, $\mathrm{N}=150$ in Zambia), compared to $93 \%$ who expressed strong desire to be involved using a variety of participatory approaches. About $53 \%$ of community members trust that policy makers are aware of their energy needs, where this perception is higher among Zambians (76\%) compared to Ugandan respondents $(41 \%)$. Of the community members who are involved in community energy projects, more than half $(56 \%)$ of the respondents believe their contributions are taken into account during decision making and implementation.

Figure 1 and Figure 2 compare the distribution of community engagement types (sampling from those respondents who are currently involved) with the preferred level of engagement (sampling from all respondents) for Zambia and Uganda, respectively. They show that across all methods of community engagement which go beyond being merely informed, respondents desire to be more deeply involved in public sector electrification projects than how people are currently being involved. Furthermore, across all types of community engagement, more Zambians prefer to be involved in community energy projects compared to Ugandans. The only exception is self-mobilisation - a process in which communities organise themselves and take initiatives independently of external institutions to develop local solutions - where $25 \%$ of Ugandan respondents prefer it compared to $9 \%$ of Zambian respondents. The most preferred form of involvement is 'Active participation' - preferred by $58 \%$ and $35 \%$ of the respondents in Zambia and Uganda respectively. 
Level of Involvement - Zambia

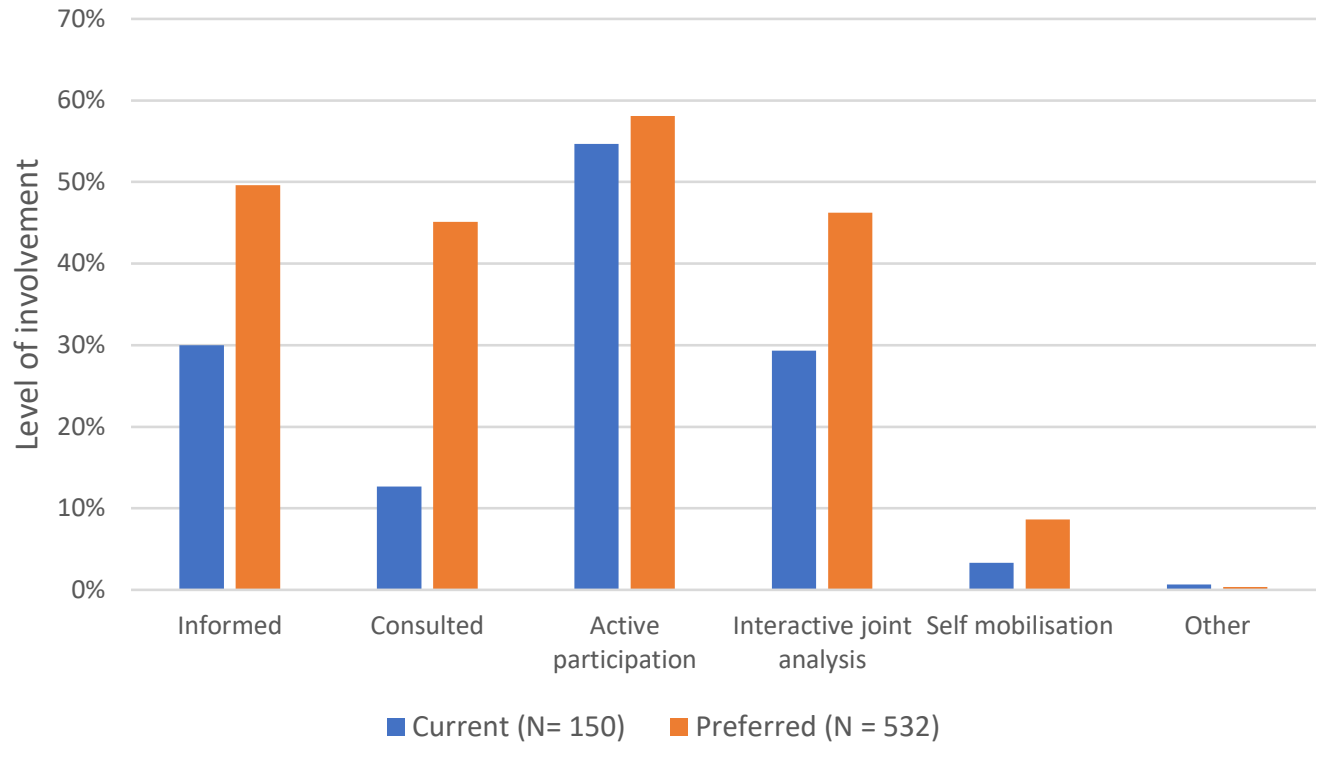

Figure 1: Current versus preferred community engagement levels in energy access-related initiatives with the public sector in Zambia (multiple answers possible)

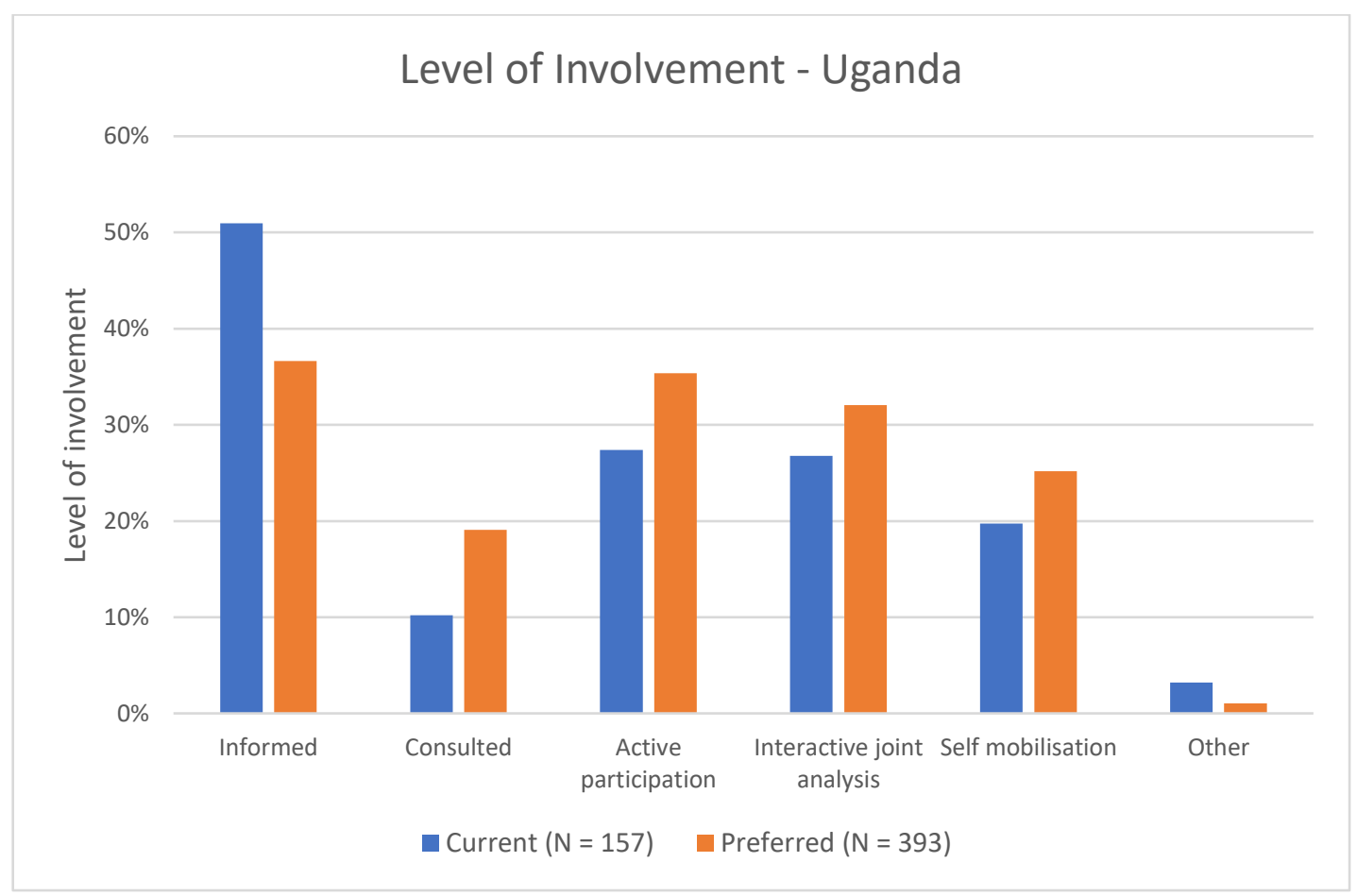

Figure 2: Current versus preferred community engagement levels in energy access-related initiatives with the public sector in Uganda (multiple answers possible) 
A significant challenge for efficient and effective community engagement is the many different sources of information on electrification which exist in the sampled rural communities. Five key different information channels exist that are used by over $20 \%$ of respondents, yet none of the information channels is used by more than $37 \%$ of respondents, indicating a significant spread of energy-related information sources. More Zambians (45\%) go to the Rural Electrification Agency (REA) for their energy needs compared to only $14 \%$ in Uganda. More Ugandans approach energy business agents in their communities for information compared to Zambia. However, this varies widely by region from 84\% in Central Uganda to 19\% in Western Uganda and only 3\% in Southern Zambia. There are only marginal differences by gender, but notable ones in terms of education and income levels. Those with high education levels engage more with energy businesses (47\%) compared to those with low education (32\%). In addition, a higher percentage of community members with low education trust REA as an information source (42\%) compared to the college-educated (19\%). Comparing income levels, the more affluent prefer to get information directly from company agents (53\%) and hardly use the community leaders $(6 \%)$ and local authorities (13\%) as sources of information compared to lower income groups. While almost half of the community leaders (49\%) prefer to get information from REA, only $17 \%$ of local businesses rely on REA for information.

4.1.2.2 Socio-economic attributes influencing community interactions with the public sector Individual socio-economic attributes such as gender, age, income and education could potentially influence the level of community engagement. Figure 3 shows the influence of selected attributes on current levels of community engagement in the two countries. The most notable difference relates to education levels. Of all college-educated respondents, $45 \%$ are involved in community engagement, while only $12 \%$ of all people without a formal education are. However, there is a less distinct pattern across gender and income level groups, the latter indicating the decoupled nature of affluence and decision-making in rural communities. While less than $30 \%$ of the poorer community members $(<500$ Zambian Kwacha (ZMW) monthly income) and the more affluent (> 6000 ZMW monthly income) are involved, over $40 \%$ of the middle-income group are involved in community energy projects. Limited involvement of the more affluent respondents is because they prefer and can afford to pay for energy services or technologies and get service faster than waiting for bureaucratic public service delivery that often takes long to materialise. One such affluent respondent in Uganda commented "..we have waited for REA to extend electricity services to our village since I was born but it has failed to deliver. I therefore decided to buy a home solar system for lighting and pumping water in my farm". 


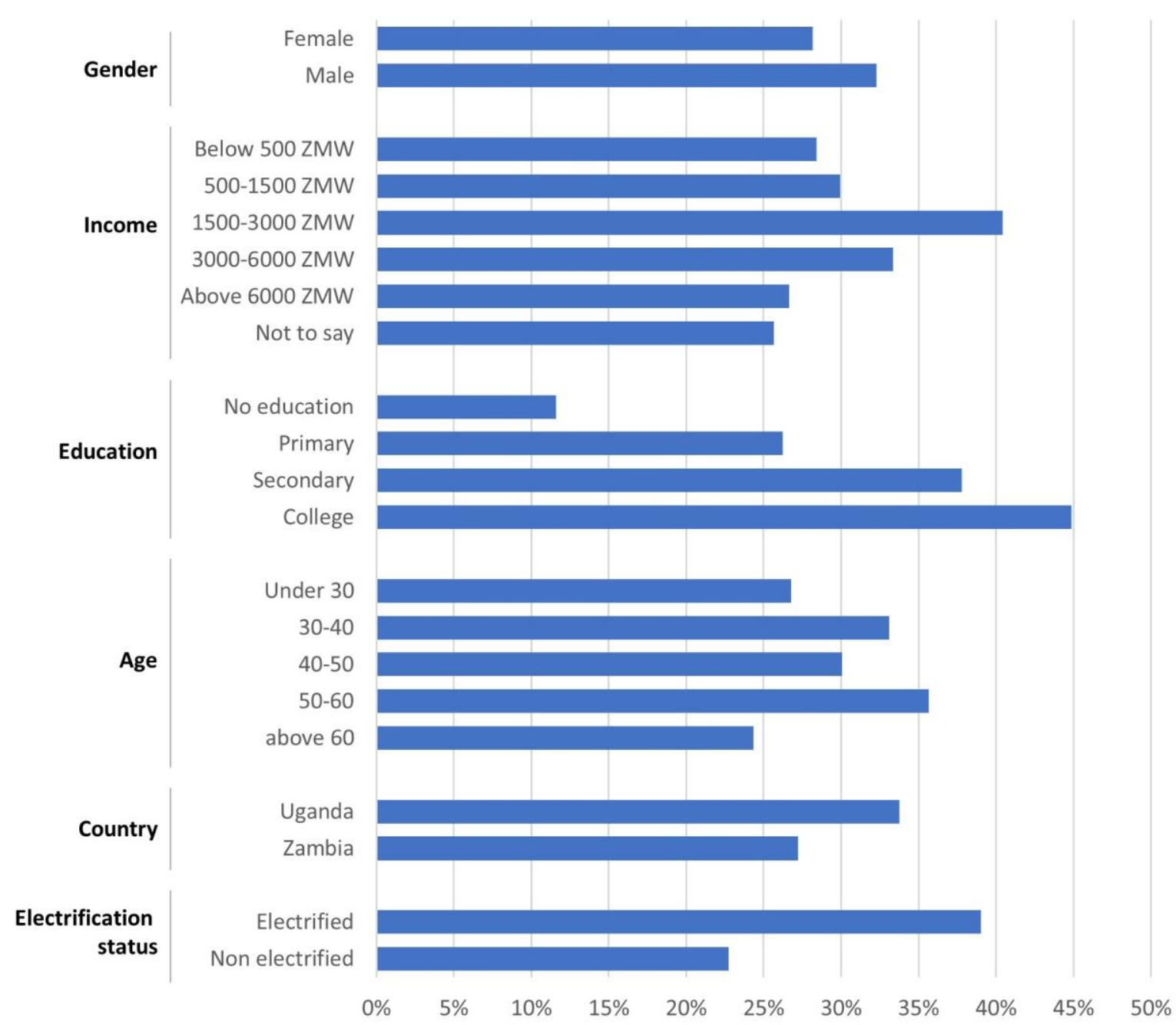

Figure 3: Share of total respondents with respective attributes who are involved (at least informed) in community engagement in public sector electrification initiatives $(N=977)$

Moreover, community leaders are more involved in decision-making than ordinary households and businesses, but the overall number is only $43 \%$. This demonstrates the significant gap in community engagement in both countries as community leaders represent the first line of community hierarchy through which participation of community members is expected. There are also significant differences in level of involvement by status of electrification when broken up by sub-national regions where the survey was administered, as shown in Table 2. Respondents in certain regions (Central in Uganda, Southern in Zambia) are much more likely to have been involved in public sector electrification initiatives than in others (Northern in Uganda, Eastern in Zambia), demonstrating the influence of other region-specific factors. Electrified community members are more involved than non-electrified (40\% vs $23 \%$ ) in both countries. 
Table 2: Share of total respondents who are involved (at least informed) in community engagement in public sector electrification initiatives by region $(N=1007)$

\begin{tabular}{|l|l|l|l|l|l|l|l|}
\hline \multirow{2}{*}{$\begin{array}{l}\text { Electrification } \\
\text { status }\end{array}$} & \multicolumn{7}{|c|}{ Country/region } \\
\cline { 2 - 8 } & \multicolumn{2}{|c|}{ Zambia } & \multicolumn{5}{c|}{ Uganda } \\
\cline { 2 - 8 } & Eastern & $\begin{array}{l}\text { Souther } \\
\mathrm{n}\end{array}$ & Central & Eastern & Northern & $\begin{array}{l}\text { Wester } \\
\mathrm{n}\end{array}$ & \\
\hline Electrified & $38 \%$ & $53 \%$ & $72 \%$ & $29 \%$ & $13 \%$ & $30 \%$ & $40 \%$ \\
\hline Non- electrified & $12 \%$ & $76 \%$ & $44 \%$ & $26 \%$ & $16 \%$ & $6 \%$ & $23 \%$ \\
\hline Total Involved* & $\begin{array}{l}17 \% \\
(78)\end{array}$ & $\begin{array}{l}71 \% \\
(72)\end{array}$ & $\begin{array}{l}69 \% \\
(84)\end{array}$ & $\begin{array}{l}28 \% \\
(29)\end{array}$ & $\begin{array}{l}15 \% \\
(17)\end{array}$ & $\begin{array}{l}23 \% \\
(27)\end{array}$ & $\begin{array}{l}30 \% \\
(307)\end{array}$ \\
\hline
\end{tabular}

*Number is brackets represents the number of respondents

There is significant variation in the level of community engagement and engagement approaches across regions in the two countries. While about $70 \%$ are currently involved in Central Uganda (Kalangala) and Southern Zambia (Choma), only 15\% and 17\% are involved in Northern Uganda (Amuru, Gulu) and Eastern Zambia (Katete). Similarly, the engagement approaches vary significantly by region, for instance from less than $2 \%$ for Southern Zambia to over $60 \%$ in Central Uganda for 'just informed' approach.

Analysing community engagement preferences rather than actual current engagement, we find a higher proportion of uneducated community members (64\%) who want to only be informed rather than having active participation (compared to $30 \%$ for the college-educated). Across income groups, there is a varied preference for involvement - the most affluent (> 500 USD per month) prefer to be consulted (57\%) compared to other income brackets $(<35 \%)$. More households $(48 \%)$ prefer to be consulted than businesses and community leaders $(<40 \%)$ but more community leaders $(66 \%)$ prefer active participatory decision making compared to the other respondents (40-49\%). Furthermore, nonelectrified community members prefer to be involved in decision making across all engagement approaches $-51 \%$ prefer to be informed while $42 \%$ prefer to be consulted compared to $35 \%$ and $25 \%$ for electrified respectively. The same applies to active participation, interactive decision making, and self-mobilisation approaches. Furthermore, although there is general convergence across age groups, there are some slight differences in preference to community engagement approaches. Young people ( $<30$ years old) prefer more interactive decision making while older people ( $>60$ years) prefer to be merely informed. Given the diversity in community engagement preferences, it can be concluded that there is no one-size fits all approach to community engagement. There is, therefore, a need to identify appropriate approaches for specific communities, to ensure adequate involvement through relevant means. 


\subsection{Community engagement and the private sector}

\subsubsection{The energy businesses' barriers for needs-centric community engagement}

Most energy businesses interviewed in Uganda and Zambia engage communities in the implementation of their projects, but do so in a limited way. For solar home system companies, pre-sales interactions with communities are almost exclusively focused on companies' sales teams trying to locally market and sell their products. For mini-grid companies, community engagement was usually limited to several brief site visits and, in the case of Uganda, one-day town-hall meetings where all community members were invited to ask questions about the mini-grid and the tariff they would have to pay.

Our interviews reveal three main reasons why businesses limit community engagement activities. Firstly, most companies hold a strong belief that they are fully aware of community needs, and thus do not see sufficient benefits of engaging more deeply with communities. Of the 28 companies interviewed, 27 said they know the community needs well or very well. Their types of community engagement instead focus on explaining and demonstrating their technological solutions and attempting to communicate their value for community members. The vast majority of private-sector actors interviewed were convinced that their products were already ideally suited to address community needs, or, as one Ugandan solar off-grid company put it, "[w] sell our product to you, we solve your problem." Another company operating in several East and Southern African countries mentioned that their solar home systems were "exactly what people need in the communities. They pay too much for paraffin lights, or they do not have any light at all. Our solution fits their need for lighting and socialising very well." This often implied a de-prioritisation of business-led community engagements focused on scrutinising and understanding community needs.

Secondly, several companies have mentioned doubts as to whether in-depth community engagement is valuable for the solutions they offer. Over $80 \%$ mentioned that the current level of community engagement is sufficient, even if no in-depth community engagement had taken place. A Ugandan minigrid company said that "[w]e design mini-grids based on a rough idea of what the community would need." Several companies active in Uganda said that the level of community engagement was limited to one to three "one-hour visits". Some companies have expressed doubt as to whether the communities had a good understanding of their own needs, claiming instead that they knew them better. A company active in Uganda stated: "We use our experience [when defining our solutions]. It's amazing that you go to communities and some of them don't even know what they need."

Thirdly, interviewees demonstrated a limited willingness to engage in communities if there are no direct monetary gains from doing so. This is especially salient as the energy access sector in Uganda and Zambia is under severe cost pressure, with several companies highlighting struggles with tight financing and price limits for what people can afford. The limited monetary gains from community engagement can have different reasons, depending on the technology offered. A solar home system company mentioned that their solution is too standardised to be impacted by community engagement. In one 
example, a number of mini-grid sites were bundled in a package and auctioned off to the lowest bid. As long as minimum reliability levels could be ensured, the winning bid depended solely on cost. Hence, there was no incentive for businesses to engage deeply with communities. Indeed, the company-led community engagement for these sites was limited to one hour-long site visit of each site before the contract was awarded to the winning company. One mini-grid company participating in the bid described a lack of motivation for deeper community engagement in this process, saying that "we saw many villages that day. It was just not possible to get more from this than the big picture of the site.... The sites looked fairly similar to us."

At the same time however, as a counterfactual, several mini-grid companies view community engagement as a sine-qua-non where communities are a necessary part of their business model. This is driven by mini-grid companies either focusing on productive use of energy which requires community involvement or relying on community ownership of their mini-grids to be profitable. Selling energy for productive use is only viable if companies understand its potential in the respective communities, in turn requiring interactions with communities to identify energy needs. As an international mini-grid developer explains, "[m]ost communities have people that want to better themselves [through productive use of electricity], get richer, be more organised. These groups are very often led by women. As a company, we just have to be prepared, be more organised, and find the right partners within the communities." Similarly, a Zambian company explains that "[w] e have learned that we need to engage with local communities and develop capacity within the community because when we start to operate the project we depend on the local people." Also, businesses who rely on community ownership similarly depend on community engagement for the viability of their projects. Another Zambian company mentions that "[w]e have a significant amount of meetings with community people. [Our] model requires that we have to train part of the community on how to use [the mini-grid], to be able to manage the project, to ensure its sustainability." Other companies with a community ownership component similarly see working with communities as crucial for making money, saying that " $[t]$ he idea for the community was that we can collectively pay for this mini-grid and then own and operate $i t^{\prime \prime}$.

\subsubsection{Community perspective}

\subsubsection{Types of community engagement with energy businesses}

The community survey showed that there is a gap in interaction between community members and energy companies in both Uganda and Zambia. About half of the community members are not aware of energy companies operating in their localities and of those aware about $70 \%$ have interacted with them. Further, only $43 \%$ are satisfied with the energy services provided, and over half of respondents (52\%) have experienced problems with energy businesses. Conversely, 57\% indicate that the energy 
company they are interacting with has not been able to meet their energy-related needs. Moreover, 58\% of respondents indicate that no discussion of energy needs has taken place with their energy company (this number increases to $76 \%$ if those respondents who have never had interactions with energy companies are also counted), suggesting that at least three quarters of respondents have not been able to refer their needs to energy companies.

Community members face numerous challenges when interacting with energy businesses. As shown in Figure 3, the top three challenges faced include inadequate provision of information, abrupt cutting off of prepaid services, and lack of after-sales services. All these challenges demonstrate limited knowledge and understanding of the associated energy business model by community members. This highlights the importance of relationship building and communication between energy businesses and their target communities. Almost 50\% of respondents indicated that lack of information and knowledge is the key issue for community interaction with energy providers, but this is less of a problem in Uganda than in Zambia. About $40 \%$ of the community members are not happy that energy companies cut off prepaid electricity services without prior notice or adequate communication - again this is a much bigger problem in Zambia than Uganda. Associated with this lack of clarity around the business model is the perceived lack of after sales service by energy companies. About a third of the community members regard poor after sales service as a key problem. This coincides with an absence of follow up mechanisms that ensure easy access to energy companies by community clients. Poor installations are also a problem for $25 \%$ of the respondents and this could be linked with poor system performance.

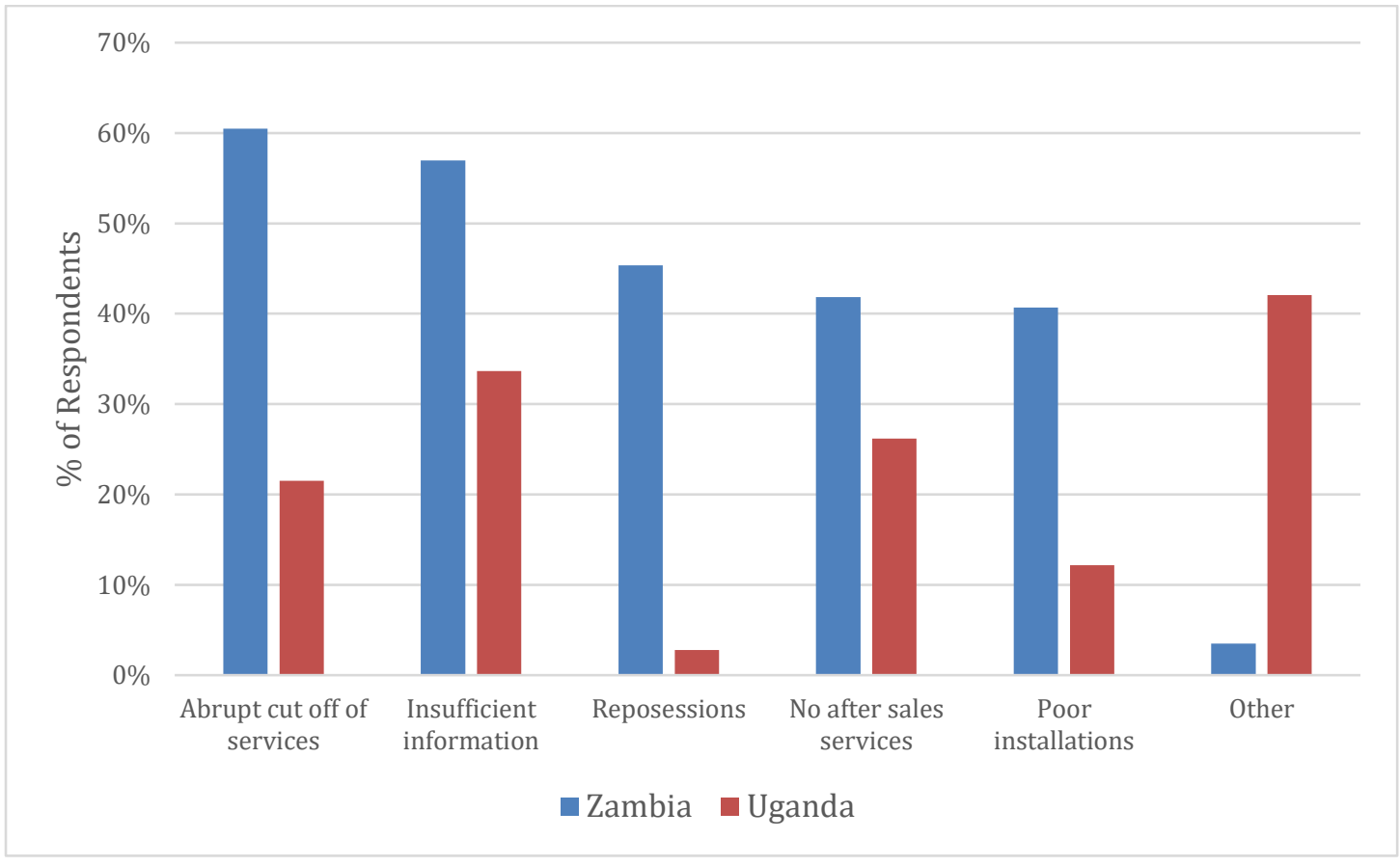

Figure 4: Key challenges encountered by community members during interactions with energy companies $(\mathrm{N}=193)$ 
The various information channels in existence (see section 4.1.2) do not lead to a well-informed customer base. Only $34 \%$ of the respondents that have interacted with energy companies indicated that the companies discussed their energy needs with their clients. About $50 \%$ of the electrified community members indicated that they were consulted during the planning of the electrification scheme they benefited from. To get connected to electricity, the majority of electrified community members (about $40 \%$ ) had to conduct their own investigations and approach energy companies. This is in contrast with $30 \%$ of the electrified community members that were approached by energy companies and about $10 \%$ who were connected as part of a community electrification programme. In addition, electrified community members obtained information on electricity and its benefits mostly from neighbours and friends (about $40 \%$ ) compared to other sources of information such as energy companies (23\%), media such as TV/radio (23\%), family members (13\%), local community leaders (20\%), and schools and churches (14\%).

\subsubsection{Socio-economic attributes influencing community interactions with energy businesses}

Our results show that on average, socio-economic attributes of respondents have a limited impact on whether or not community members report challenges in their interaction with energy businesses, with the exception of income levels and, to a lesser degree, education levels (Figure 4). More high-income community members (up to 67\%) report challenges with energy companies compared to low-income groups (30\%). Similarly, the more educated have experienced challenges with energy companies (43\% for college educated) compared to those with less education (19\% for those with no education). 


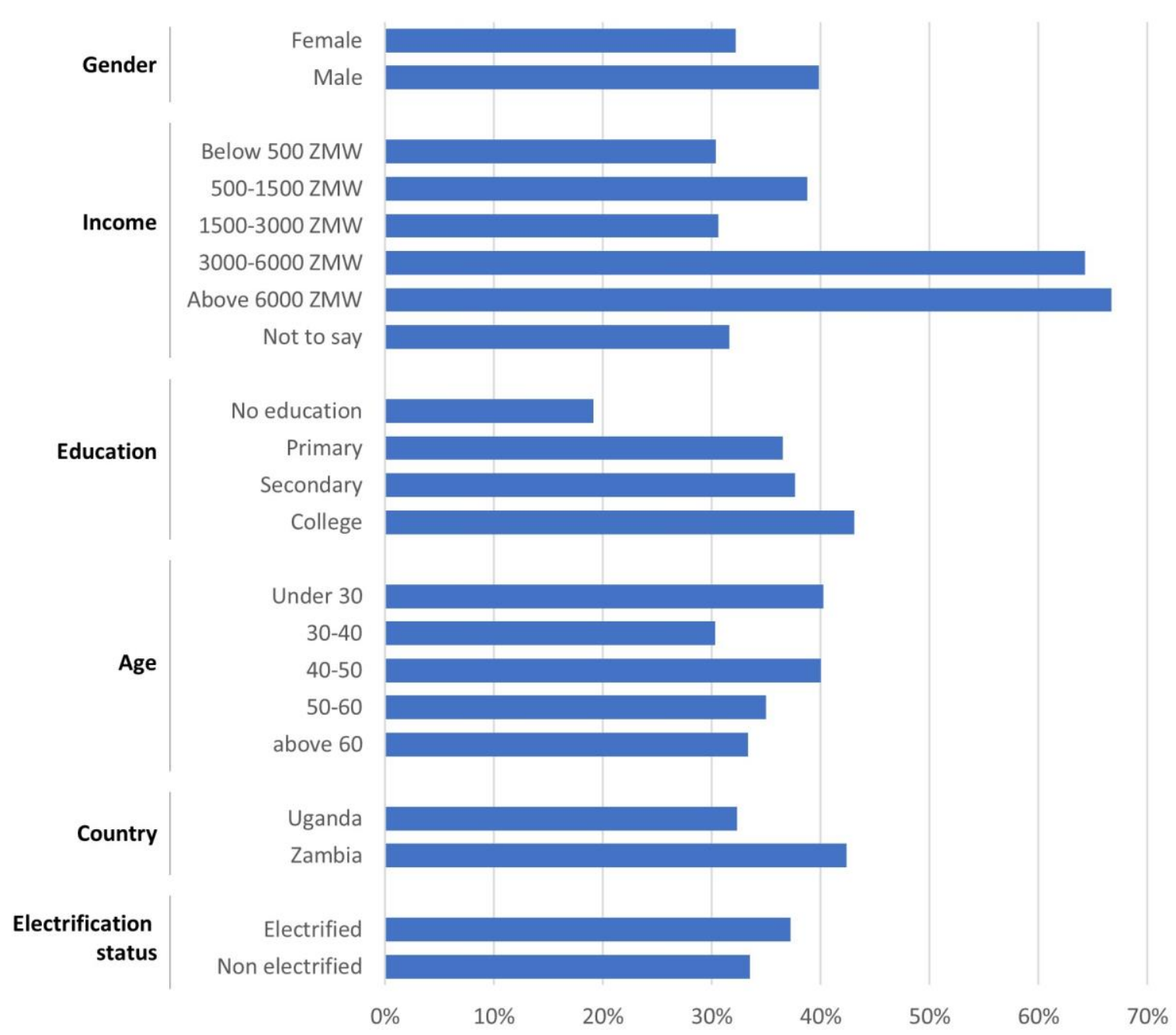

Figure 5: Share of those respondents who have interacted with energy companies and have experienced some kind of salient challenge in these interactions $(N=524)$

However, similar to the findings with respect to the public sector, our results indicate that significant regional differences exist. While the level of awareness of energy companies is fairly high in Uganda (over 70\%), it is considerably lower in Zambia (less than 40\%). Awareness is very high in Central Uganda (>95\%), Western and Eastern Uganda (about 70\%), but drops below 50\% in Northern Uganda and almost 10\% in Southern Zambia. This generally follows the electrification levels within the sampled regions which is linked to the proximity of these regions to the national capitals where most of the energy companies operate from. As shown in Table 2, electrification levels are high in Central Uganda (72\%), are lower in Eastern Uganda (38\%) and Western Uganda (30\%), and much lower in Northern Uganda (13\%). Eastern Zambia and Southern Zambia also have low electrification at 29\% and 38\% respectively. Moreover, service satisfaction levels vary widely by region: In Western Uganda, only 20\% 
of respondents are satisfied with their electricity services, whereas roughly $70 \%$ are satisfied in Southern Zambia and Central Uganda.

Of the key challenges, information availability is problematic mostly for the uneducated $(70 \%$ cited inadequate information as a major challenge) compared to $30 \%$ for the college educated. Repossessions are also a major problem for the uneducated with about half being unhappy about it. In contrast, only $15 \%$ of college educated members are affected by repossessions. After-sales services is a fairly uniform problem to everyone (34 - 44\% of respondents across income levels encountered this challenge). There is therefore an opportunity for energy businesses to educate potential clients and improve understanding of business models and manage expectations. We furthermore find some evidence for a gender disparity in access to information as there is generally higher awareness among men (60\%) than women (47\%). Analysing all respondents' preferred mode of engagement with the private sector, the majority of community respondents (56\%) prefer that local government institutions (such as the district or local councils through either the district administrator or local council chairperson) lead community engagement. About $44 \%$ of respondents prefer the process to be led by the local ward councillors while $35 \%$ prefer the local Member of Parliament. Only 20\% prefer community engagement to be spearheaded by business association against $18 \%$ who prefer women's groups and $16 \%$ who prefer churches. There is limited desire for self-initiative (7\%). Differences in preferences exist across regions in both countries. For instance only $4 \%$ in Southern Zambia prefer local government led community engagement. In addition, only $20 \%$ prefer councillors to lead in Eastern Uganda against about $60 \%$ in Central Uganda. 


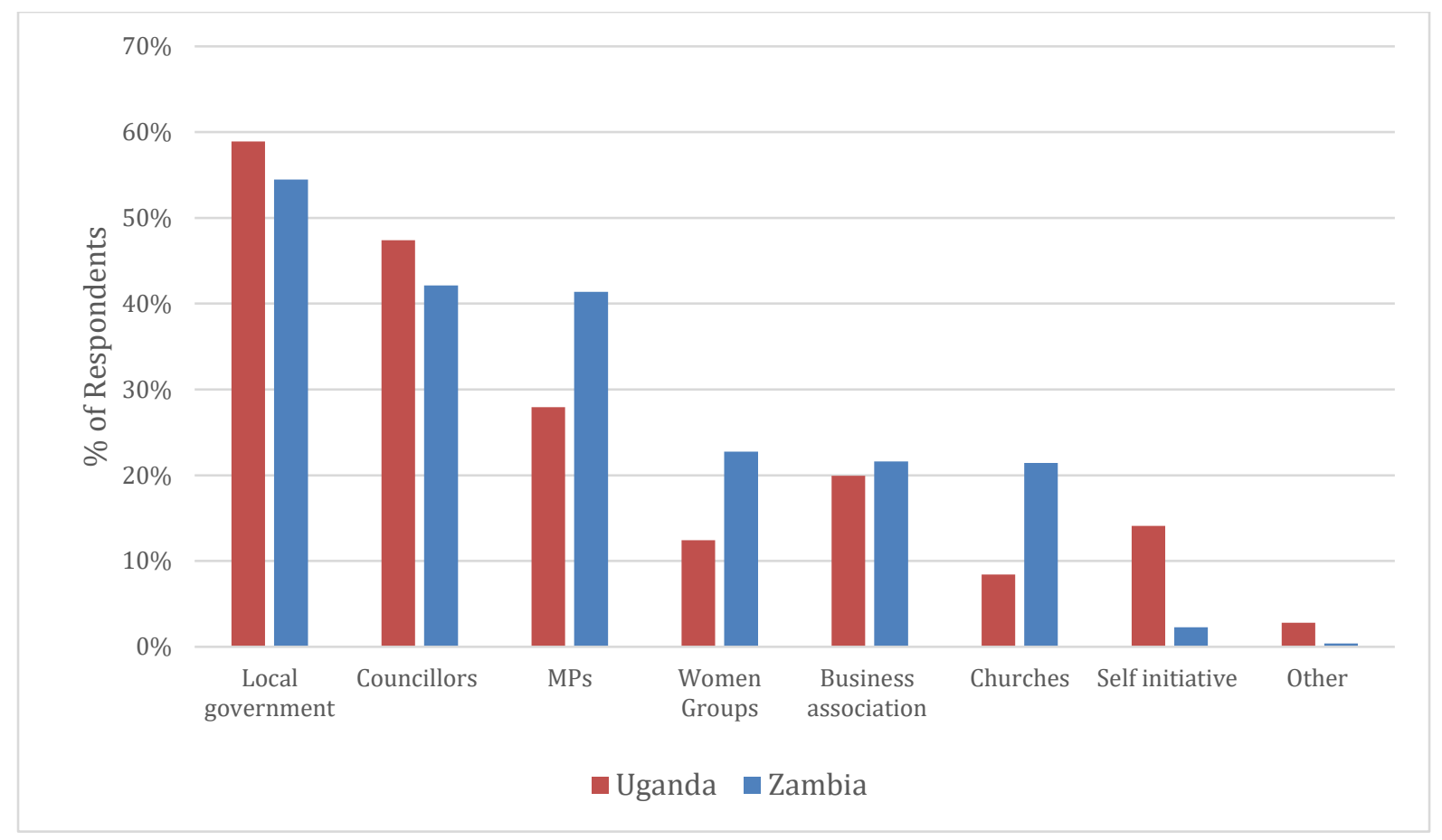

Figure 6: Preferred actor platform of communities to represent their energy needs $(N=449)$

\section{DISCUSSION}

\subsection{Barriers for needs-centric community engagement}

Existing literature suggests that the level of community engagement required to link rural electrification with improved development outcomes for communities is difficult to achieve in practice. Analysing community, government and business interactions allows us to develop a more nuanced perspective on community engagement governed by a people-private-public partnership maxim. We integrate the perspective of communities where typically their views about engagement are assumed, for instance that more and deep engagement is always better.

Our findings on community-government interactions suggest that there is a large disconnect between the extent and the types of engagement that communities would like to see and what is happening on the ground. The public sectors in both Uganda and Zambia exhibit vertical and horizontal interaction dysfunctionalities, while communities desire more in-depth and needs-centric engagement. This is consistent with existing literature that has identified a gap in replicating community engagement models that go beyond merely informing or consulting communities about rural electrification plans [13] and with findings attesting a high level of sophistication and maturity of rural communities in Uganda and Zambia with respect to energy access issues [65]. The combination of community surveys and interviews with the public sector allows us to identify several barriers to overcoming this gap. To start 
with, the considerable regional variation we find in the experience of and desire for different depth and means of community engagement points towards the importance of context for community engagement, and reflects the fact that currently there are no clear national guidelines for engaging with communities in policy development or in project implementation. The types of community interactions which are regulated by the Ugandan and Zambian governments most notably do not include how community needs are captured and integrated into energy access offerings. The fact that some regions clearly stand out in their approach to engagement however suggests potential for learning and the development of guidance to benefit all regions and to support equality in development outcomes. Furthermore, not all community members want to be engaged in the same way. Many, for instance on average those with low levels of education, favour an approach of being informed rather than being actively involved. Allowing for some variation in the types of engagement efforts and particularly in the identification of community members to be involved in different phases of policy and project development is thus critical. Moreover, our findings on community-business interactions suggest there is a disconnect between what communities want and how energy companies are currently engaging. This stems from a lack of understanding among energy companies of the benefits of engagement. At present, their engagements are generally not designed in ways that enable an understanding of community needs. This limits the extent to which the information companies gain from interactions with communities can be of value to them and ultimately to the communities they serve. Consistent with the literature, we find that there is a focus on technological solutions by energy companies and not on needs [28]. The challenges communities identify concern the way in which energy services are provided, for instance the prepaid service model and the lack of continued support for services after installation.

\subsection{Integrated community engagement model for needs-centric energy access}

The international and national push to accelerate electricity access in SSA, combined with the increasing rise of the private sector in addressing this challenge as well as the importance of meeting communal needs [15], has created tensions between policy makers, the private sector and target communities on how best to plan and implement electrification projects [13].This multi-actor setting requires close collaboration between the actors involved. While the need for community-centric electrification approaches is well-documented, there is a limited understanding in literature on how these collaborations between key actors in the context of needs-centric energy access can be fostered [21]. Indeed, the barriers for needs-centric community engagement we identify make it difficult to achieve meaningful community engagement in rural electrification in SSA. At the same time however, they provide useful insights as to how these can be addressed. This section, supported by prior findings from the literature, builds on the barriers identified in section 5.1, and suggests a set of design recommendations for integrated, needs-centric community engagement [34,39]. These recommendations are informed by a complementary top-down and bottom-up approach. Bottom-up approaches to community engagement have been developed where for example communities and 
energy businesses shape shared visions for rural electrification [50]. Our results confirm the importance of involving communities more deeply than is currently the case, but, crucially, they also show some of the barriers associated with doing this in practice, especially considering existing inequalities. The multitude of stakeholders and the scale of the energy access problem implies efficiency and effectiveness gains from combining roles for these stakeholders within integrative approaches of rural development [26]. While needs-centric community engagement requires a bottom-up role for communities, in order for it to be effective in overcoming barriers and to lead to scalable change, both the private sector as the key energy access implementing body as well as the public sector as the topdown policy-maker play crucial roles. We formulate integrated community engagement design approaches aimed at each of the interlinkages between the three key stakeholder groups, namely the public sector, the private sector, and communities, addressing both directions of the respective interlinkage separately. These design approaches comprise both strategy definition and its operationalisation (cf. [66]). By combining these approaches across the six interlinkages, Figure 7 presents an encompassing guideline to foster integrated community engagement for needs-centric energy access.

\subsubsection{Interlinkages with public sector as the basis}

Firstly, our findings indicate a lack of an integrated policy strategy for community engagement, and overly broad regulations which do not sufficiently account for the large subnational differences in community engagement desires. In response, there appears to be merit for the public sector in clearly specifying the goals for community engagement in a top-down fashion. Energy businesses require support and guidance in developing ways to engage with communities that integrate a focus on longterm needs. In addition, the public sector could foster community engagement by creating regulatory or financial incentivises for companies to do so. At present, requirements for the private sector in Uganda and Zambia to engage with communities are translated into specific instruments as part of the licensing process, but there is no overall strategy that specifies the goals of community engagement. Our results signal that community members encounter markedly different challenges in Uganda compared to Zambia. Hence, involving community representatives to tailor both policy strategy and instruments to the local context is critical. In practice, this could be included by requiring companies to engage with communities at certain stages following on from project implementation. These goals are likely to involve multiple national ministries and regulators, which would require efficient and transparent processes for the ministries of energy and local government to share information and incorporate feedback into policymaking.

Secondly, our results suggest that communal members on average want to be considerably more actively involved in electrification projects. The current way of involving community members in electrification projects leads to most community members either not being consulted or being merely informed. In response, the public sector could expand its regulatory framework to tailor the means of 
engagement to community preferences. Instead of expecting rural communities to be able to translate their needs directly to the private sector in a strictly bottom-up fashion, there is an opportunity and a mandate for national governments to strongly facilitate community needs to be better understood and integrated. Traditional leaders are known to have the potential to be partners for constructive engagements for private and public actors in the context of rural development projects [67], with the degree of community embedment of the Chiefs being important determinants. Depending on context, this may require the public sector to build capacities aimed at the Chiefs and other traditional leaders to help implement clear communication channels between Chiefs and their respective communities and increase their drive to report the needs of their communities to government officials [67]. Furthermore, community representation could be more formally embedded into decision-making processes, for instance by opening up the existing public-private stakeholder meetings on electrification to community representatives. Our results strongly suggest that the type of community representatives or local organisation that makes sense to include will vary across regions and may change as the needs of local communities evolve. Any public sector strategy to enable needs-centric community engagement must therefore be flexible enough to accompany different modes of representation.

\subsubsection{Interlinkages with private sector as the basis}

Thirdly, we find that those companies which engage deeply with communities see value for their business in understanding end-user needs, while many energy businesses are unaware of these benefits. Current interactions are frequently superficial and focus on existing solutions. Those companies with deep links into communities have made incremental or significant adjustments to their business models in their target communities. Such business model changes allow companies to be flexible enough in the types of solutions they offer in order to monetise known and newly identified needs [8], providing them with a profit-oriented incentive for needs-centric community engagement. Our results thus point to mutual benefits of both energy companies and communities in extended engagements: They allow communities to voice their needs, while they provide an opportunity for in-depth market analyses and a source for business model innovation and, in some cases, value chain expansions for companies. Critically, these types of repeated, in-depth engagements require an incentive to consider a longer time horizon for engagement than is currently the case [51].

Fourthly, our interviewees have reported challenges surrounding transparency on the ground. There is a need for a stronger collaboration between the private and public sector to improve the connection between community engagement processes for policy development, and for the planning and implementation of projects. Utilising the private sector, i.e. the implementing organisation of the majority of electrification efforts, to connect lessons from community engagement in projects via regular and quick information flows represents a clear opportunity to embed these lessons into rural electrification policies. 


\subsubsection{Interlinkages with community as the basis}

Fifthly and sixthly, to act on their desire to communicate immediate energy needs to energy businesses as well as to provide direct input to policy making, communities can utilise the engagement opportunities created by both energy companies and the public sector. As our results indicate, satisfactory inclusion of community energy needs can hinge on different, context-specific actors and means of engagement, requiring communities to choose ways of engaging with private and public sector actors. Given the considerable national and subnational differences in energy needs and preferred engagement modes, and given the notable shortage of institutionalised communication channels between communities and government, pro-active communication is a potential pathway for communities to make their respective needs transparent. Our findings suggest that while businesses may believe they know community needs, their degree of actual community engagement is often highly limited. Notably, in Ghana, a country hailed for its remarkable success in increasing rural electrification in Africa [3], governmental policies attributing agency to communities and demanding pro-activeness have been a significant part of their success [68]. It is key to note that increased representation of rural communities through their traditional leaders on local and national levels raises the complex question as to which extent communal leaders such as Chiefs are accountable to villagers in representing their interests. Chiefs in Zambia commonly exert a high degree of influence, lobbying and negotiating for the development needs of their chiefdom. Such structures are less pronounced in Uganda, however large regional differences exist. This challenge necessitates to be mindful of the local socio-politics of leadership with respect to pro-active community engagement. It should be noted that a community being pro-active about communicating its preferences alone is unlikely to be sufficient for businesses and policy makers to take community needs on board, instead requiring a mix of integrated measures across stakeholders (Figure 7).

Moreover, our results indicate that education plays a critical role in determining the degree of community members' involvement, suggesting that different modes of engagement are likely necessary to avoid biases in capturing needs, as well as a noteworthy potential co-benefit of improving education levels in rural communities [43]. Our results suggest that a critical issue centres around trust, with highly educated people displaying limited amounts of trust into public sector institutions: Similar observations of trust into governmental versus private institutions as source of information and the correlation with educational levels have been made with regard to trust in private versus state-owned media across Africa [8]. Moehler et.al., [69] discovered that the level of education of a respondent was directly related to the levels of trust in the private versus the state media. The level of education negatively correlated with the trust in state media which Moehler et.al., [69] explain with the lower ability of less educated individuals to detect and penalise pro-incumbent bias in state media. In the case of Uganda and Zambia, this explanation would mean that less educated people have limited resources to assess the performance of REA. Lower education levels also tend to correlate with lower income and vice versa. 
Better educated respondents tend to have a higher income, a correlation that could be confirmed from previous empirical findings from both countries $[9,10]$. An inclusive community-level process has the potential of identifying electrification needs of groups such as those with low education levels who are less likely to want to be actively involved in electrification projects themselves.

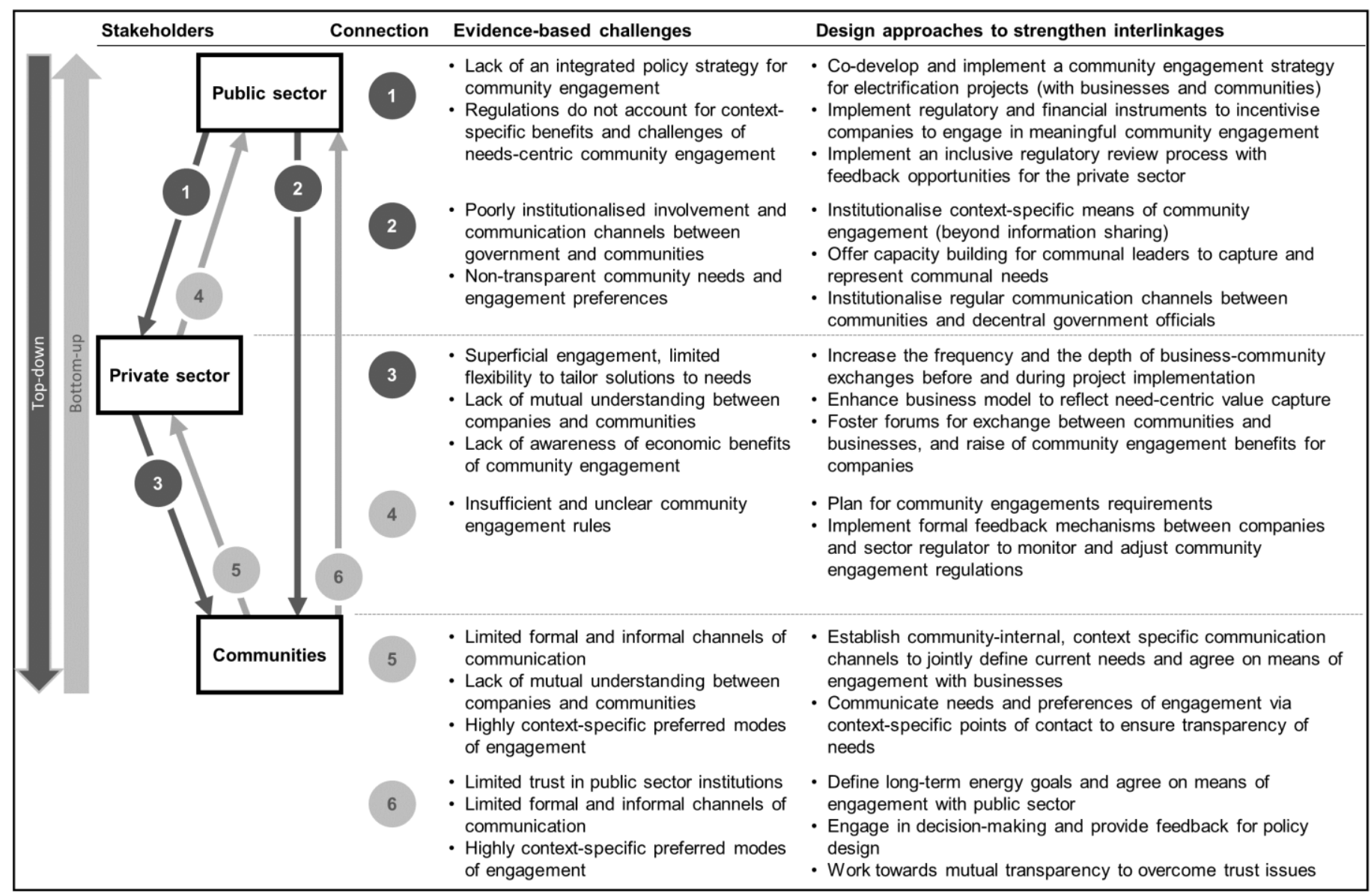

Figure 7: Integrated community engagement model for capturing energy access needs

\section{CONCLUSION}

Needs-centric community engagement has not been broadly implemented in the energy access realm, even though it has been long called for in theory and practice. In this paper we analyse current community engagement activities in Uganda's and Zambia's rural electrification sectors. We collected separate data from communities, public sector stakeholders and energy companies to understand the barriers to needs-centric community engagement, and how to foster a people-private-public partnership approach to needs-centric community engagement. Our findings suggest that there are significant gaps between the depth of engagement communities desire and how public and private sectors currently engage. We identify several barriers for engagement between communities and both public and private 
sectors. In the public sector, there are vertical and horizontal disconnects as well as resource constraints preventing effective community engagement. In the private sector, many energy companies do not see the value of community engagement. From the community perspective, while members often do not feel that their needs are adequately represented, their preferred means of communicating and representing these energy needs are highly context-specific.

In response, we identify and discuss several design approaches for community engagement along the interlinkages between the public sector, private sector and communities. Together, these communityengagement design approaches form an integrated model which places community needs in electrification projects at its centre. The model relies on a combination of top-down and bottom-up approaches to embedding the needs of communities into sustainable rural electrification programmes. Key design elements include public institutions playing a catalytic role by setting an enabling environment for the energy businesses and communities to capture community needs, businesses being ready to adapt their business models towards more need-centric value capture approaches, ensuring that there are deep connections developed between all relevant stakeholders, as well as feedback mechanisms to inform strategic policy making and instrument design.

\section{REFERENCES}

[1] K. Bos, D. Chaplin, A. Mamun, Benefits and challenges of expanding grid electricity in Africa: A review of rigorous evidence on household impacts in developing countries, Energy Sustain. Dev. 44 (2018) 64-77.

[2] World Energy Council, World Energy Scenarios | 2017. Regional Perspective for Sub-Saharan $\begin{array}{lll}\text { Africa, } & \text { London, } & \text { UK, }\end{array}$ https://www.worldenergy.org/assets/downloads/Scenarios_Regional-Perspective-for-SubSaharan-Africa-1.pdf.

[3] P.A. Trotter, Rural electrification, electrification inequality and democratic institutions in subSaharan Africa, Energy Sustain. Dev. $34 \quad$ (2016) 111-129. https://doi.org/10.1016/j.esd.2016.07.008.

[4] B. Tarekegne, Just electrification: Imagining the justice dimensions of energy access and

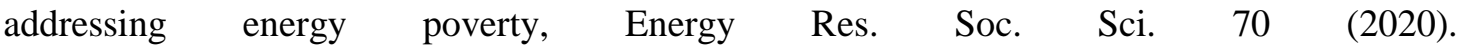
https://doi.org/10.1016/j.erss.2020.101639.

[5] K.J. Hancock, The expanding horizon of renewable energy in sub-Saharan Africa: Leading research in the social sciences, Energy Res. Soc. Sci. 5 (2015) 1-8. https://doi.org/10.1016/j.erss.2014.12.021.

[6] M.P. Blimpo, M. Cosgrove-Davies, Electricity Access in Sub-Saharan Africa. Uptake, 
Reliability, and Complementary Factors for Economic Impact, World Bank Group, 2019. http://documents.worldbank.org/curated/en/837061552325989473/pdf/135194-PUB-PUBLIC9781464813610.pdf.

[7] R. Madriz-Vargas, A. Bruce, M. Watt, The future of Community Renewable Energy for electricity access in rural Central America, Energy Res. Soc. Sci. 35 (2018) 118-131. https://doi.org/10.1016/j.erss.2017.10.015.

[8] C. Muchunku, K. Ulsrud, D. Palit, W. Jonker-Klunne, Diffusion of solar PV in East Africa: What can be learned from private sector delivery models?, Wiley Interdiscip. Rev. Energy Environ. 7 (2018) e282. https://doi.org/10.1002/wene.282.

[9] S. Hirmer, P. Guthrie, The benefits of energy appliances in the off-grid energy sector based on seven off-grid initiatives in rural Uganda, Renew. Sustain. Energy Rev. 79 (2017) 924-934. https://doi.org/10.1016/J.RSER.2017.05.152.

[10] J. Terrapon-Pfaff, C. Dienst, J. König, W. Ortiz, A cross-sectional review: Impacts and sustainability of small-scale renewable energy projects in developing countries, Renew. Sustain. Energy Rev. 40 (2014) 1-10. https://doi.org/10.1016/J.RSER.2014.07.161.

[11] J. Peters, M. Sievert, M.A. Toman, Rural electrification through mini-grids: Challenges ahead, Energy Policy. 132 (2019) 27-31. https://doi.org/10.1016/j.enpol.2019.05.016.

[12] P.A. Trotter, N.J. Cooper, P.R. Wilson, A multi-criteria, long-term energy planning optimisation model with integrated on-grid and off-grid electrification-The case of Uganda, Appl. Energy. 243 (2019) 288-312. https://doi.org/10.1016/j.apenergy.2019.03.178.

[13] M.J. Herington, E. van de Fliert, S. Smart, C. Greig, P.A. Lant, Rural energy planning remains out-of-step with contemporary paradigms of energy access and development, Renew. Sustain. Energy Rev. 67 (2017) 1412-1419. https://doi.org/10.1016/J.RSER.2016.09.103.

[14] P.A. Trotter, S. Abdullah, Re-focusing foreign involvement in sub-Saharan Africa's power sector on sustainable development, Energy Sustain. Dev. 44 (2018) 139-146. https://doi.org/10.1016/j.esd.2018.03.003.

[15] T.H.Y. Li, S.T. Ng, M. Skitmore, Conflict or consensus: An investigation of stakeholder concerns during the participation process of major infrastructure and construction projects in Hong Kong, Habitat Int. 36 (2012) 333-342. https://doi.org/10.1016/j.habitatint.2011.10.012.

[16] W. Tobiasson, T. Jamasb, The Solution that Might Have Been: Resolving Social Conflict in Deliberations about Future Electricity Grid Development, Energy Res. Soc. Sci. 17 (2016) 94101. https://doi.org/10.1016/j.erss.2016.04.018.

[17] L. Späth, A. Scolobig, Stakeholder empowerment through participatory planning practices: The case of electricity transmission lines in France and Norway, Energy Res. Soc. Sci. 23 (2017) 189-198. https://doi.org/10.1016/j.erss.2016.10.002.

[18] R. Davis, D.M. Franks, Costs of Company-Community Conflict in the Extractive Sector. Corporate Social Responsibility Initiative Report No. 66, (2014) 1-56. 
[19] G. Watkins, Lessons from Four Decades Of Infrastructure Project Related Conflicts in Latin America and the Caribbean Lessons from Four Decades of Infrastructure Project-Related Conflicts in Latin America and the Caribbean, 2017.

[20] Power Africa, Guide to community engagement for power projects in Kenya, (2018). https://www.usaid.gov/sites/default/files/documents/1860/FINAL_Guide_to_Community_Eng agement_-_Jan_17_2018_508-compressed.pdf.

[21] J. Whitton, I.M. Parry, M. Akiyoshi, W. Lawless, Conceptualizing a social sustainability framework for energy infrastructure decisions, Energy Res. Soc. Sci. 8 (2015) 127-138. https://doi.org/10.1016/j.erss.2015.05.010.

[22] J. Poncian, When government commitment meets community proactiveness: Governing gas and community engagement in Tanzania, Energy Res. Soc. Sci. (2019). https://doi.org/10.1016/j.erss.2019.01.012.

[23] C. Alvial-Palavicino, N. Garrido-Echeverría, G. Jiménez-Estévez, L. Reyes, R. Palma-Behnke, A methodology for community engagement in the introduction of renewable based smart microgrid, Energy Sustain. Dev. 15 (2011) 314-323. https://doi.org/10.1016/j.esd.2011.06.007.

[24] E.C.X. Ikejemba, P.B. Mpuan, P.C. Schuur, J. Van Hillegersberg, The empirical reality \& sustainable management failures of renewable energy projects in Sub-Saharan Africa (part 1 of 2), Renew. Energy. 102 (2017) 234-240. https://doi.org/10.1016/j.renene.2016.10.037.

[25] E. Wilson, R.G. Wood, B. Garside, Sustainable energy for all? Linking poor communities to modern energy services, 2012.

[26] S.J.D. Schillebeeckx, P. Parikh, R. Bansal, G. George, An integrated framework for rural electrification: Adopting a user-centric approach to business model development, Energy Policy. 48 (2012) 687-697. https://doi.org/10.1016/j.enpol.2012.05.078.

[27] P. Marana, L. Labaka, J.M. Sarriegi, A framework for public-private-people partnerships in the city resilience-building process, Saf. Sci. $110 \quad$ (2018) 39-50. https://doi.org/10.1016/j.ssci.2017.12.011.

[28] J. Cloke, A. Mohr, E. Brown, Imagining renewable energy: Towards a Social Energy Systems approach to community renewable energy projects in the Global South, Energy Res. Soc. Sci. 31 (2017) 263-272. https://doi.org/10.1016/j.erss.2017.06.023.

[29] P. Dwivedi, A. Dwivedi, Public community participation model for renewable energy projects in India, World Renew. Energy Forum, WREF 2012, Incl. World Renew. Energy Congr. XII Color. Renew. Energy Soc. Annu. Conf. 3 (2012) 1762-1768.

[30] I. Soutar, C. Mitchell, Towards pragmatic narratives of societal engagement in the UK energy system, Energy Res. Soc. Sci. 35 (2018) 132-139. https://doi.org/10.1016/j.erss.2017.10.041.

[31] A. Stirling, Opening up or closing down Analysis, participation and power in the social appraisal of technology, in: M. Leach, I. Scoones, B. Wynne (Eds.), Sci. Citiz. Glob. Chall. Engagem., Zed Books, London, 2005: pp. 218-231. 
[32] C. Muhoza, O.W. Johnson, Exploring household energy transitions in rural Zambia from the user perspective, Energy Policy. 121 (2018) 25-34. https://doi.org/10.1016/j.enpol.2018.06.005.

[33] J. Poncian, J. Jose, National resource ownership and community engagement in Tanzania's $\begin{array}{lllllll}\text { natural gas } & \text { governance, } & \text { Energy } & \text { Policy. } & 133 & \text { (2019) }\end{array}$ https://doi.org/10.1016/j.enpol.2019.110903.

[34] J.N. Brass, S. Carley, L.M. MacLean, E. Baldwin, Power for Development: A Review of Distributed Generation Projects in the Developing World, Annu. Rev. Environ. Resour. 37 (2012) 107-136. https://doi.org/10.1146/annurev-environ-051112-111930.

[35] G. Rowe, L.J. Frewer, A typology of public engagement mechanisms, Sci. Technol. Hum. Values. 30 (2005) 251-290. https://doi.org/10.1177/0162243904271724.

[36] S.R. Arnstein, A ladder of citizen participation, J. Am. Inst. Plann. 35 (1969) 216-224.

[37] B. Klievink, I. Lucassen, Facilitating adoption of international information infrastructures: a Living Labs approach, Lect. Notes Comput. Sci. 8074 (2013) 250-261.

[38] A. Katre, A. Tozzi, Assessing the sustainability of decentralized renewable energy systems: a comprehensive framework with analytical methods, Sustainability. 10 (2018) 1058.

[39] A. Katre, A. Tozzi, S. Bhattacharyya, Sustainability of community-owned mini-grids: Evidence from India, Energy. Sustain. Soc. 9 (2019). https://doi.org/10.1186/s13705-018-0185-9.

[40] N. Blair, D. Pons, S. Krumdieck, Electrification in remote communities: Assessing the value of electricity using a community action research approach in Kabakaburi, Guyana, Sustain. 11 (2019). https://doi.org/10.3390/su11092566.

[41] S. Feron, R.R. Cordero, F. Labbe, Rural electrification efforts based on off-grid photovoltaic systems in the Andean Region: Comparative assessment of their sustainability, Sustain. 9 (2017). https://doi.org/10.3390/su9101825.

[42] L.L. Delina, Whose and what futures? Navigating the contested coproduction of Thailand's energy sociotechnical imaginaries, Energy Res. Soc. Sci. 35 (2018) 48-56. https://doi.org/10.1016/j.erss.2017.10.045.

[43] D. Mosse, People's knowledge, Participation and Patronage: Operations and Representations in Rural Development, in: B. Cook, U. Kothari (Eds.), Particip. - New Tyranny?, Zed Press, London, 2001: pp. 16-35.

[44] S. Ma, J. Urpelainen, Distributed power generation in national rural electrification plans: An international and comparative evaluation, Energy Res. Soc. Sci. 44 (2018) 1-5.

[45] A. Ambole, J.K. Musango, K. Buyana, M. Ogot, C. Anditi, B. Mwau, Z. Kovacic, S. Smit, S. Lwasa, G. Nsangi, H. Sseviiri, A.C. Brent, Mediating household energy transitions through codesign in urban Kenya, Uganda and South Africa, Energy Res. Soc. Sci. 55 (2019) 208-217. https://doi.org/10.1016/j.erss.2019.05.009.

[46] J. Knuckles, Business models for mini-grid electricity in base of the pyramid markets, Energy Sustain. Dev. 31 (2016) 67-82. https://doi.org/10.1016/j.esd.2015.12.002. 
[47] V. Bandi, T. Sahrakorpi, J. Paatero, R. Lahdelma, Touching the invisible: Exploring the nexus of energy access, entrepreneurship, and solar homes systems in India, Energy Res. Soc. Sci. 69 (2020) 101767. https://doi.org/10.1016/j.erss.2020.101767.

[48] O.W. Johnson, V. Gerber, C. Muhoza, Gender, culture and energy transitions in rural Africa, Energy Res. Soc. Sci. (2019). https://doi.org/10.1016/j.erss.2018.11.004.

[49] S.C. Bhattacharyya, Energy access programmes and sustainable development: A critical review and analysis, Energy Sustain. Dev. $16 \quad$ (2012) 260-271. https://doi.org/10.1016/J.ESD.2012.05.002.

[50] A. Eitan, L. Herman, I. Fischhendler, G. Rosen, Community-private sector partnerships in renewable energy, Renew. Sustain. Energy Rev. 105 (2019) 95-104. https://doi.org/10.1016/j.rser.2018.12.058.

[51] F. van der Vleuten, N. Stam, R.-J. van der Plas, Putting rural energy access projects into perspective: What lessons are relevant?, Energy Policy. 61 (2013) 1071-1078. https://doi.org/10.1016/J.ENPOL.2013.05.087.

[52] F. Bowen, A. Newenham-Kahindi, I. Herremans, When suits meet roots: The antecedents and consequences of community engagement strategy, J. Bus. Ethics. 95 (2010) 297-318. https://doi.org/10.1007/s10551-009-0360-1.

[53] J. Terrapon-Pfaff, M.-C. Gröne, C. Dienst, W. Ortiz, Impact pathways of small-scale energy projects in the global south - Findings from a systematic evaluation, Renew. Sustain. Energy Rev. 95 (2018) 84-94. https://doi.org/10.1016/j.rser.2018.06.045.

[54] A. Mubita, M. Libati, M. Mulonda, The Importance and Limitations of Participation in Development Projects and Programmes, Eur. Sci. Journal, ESJ. 13 (2017) 238. https://doi.org/10.19044/esj.2017.v13n5p238.

[55] N. Komendantova, M. Riegler, S. Neumueller, Of transitions and models: Community engagement, democracy, and empowerment in the Austrian energy transition, Energy Res. Soc. Sci. 39 (2018) 141-151. https://doi.org/10.1016/j.erss.2017.10.031.

[56] B.K. Sovacool, J. Axsen, S. Sorrell, Promoting novelty, rigor, and style in energy social science: Towards codes of practice for appropriate methods and research design, Energy Res. Soc. Sci. 45 (2018) 12-42. https://doi.org/10.1016/j.erss.2018.07.007.

[57] The World Bank, World Development Indicators, Washington DC, 2019.

[58] R. Alence, Political institutions and developmental governance in sub-Saharan Africa, J. Mod. Afr. Stud. 42 (2004) 163-187. https://doi.org/10.1017/S0022278X04000084.

[59] I. Wanasika, J.P. Howell, R. Littrell, P. Dorfman, Managerial Leadership and Culture in SubSaharan Africa, J. World Bus. 46 (2011) 234-241. https://doi.org/10.1016/j.jwb.2010.11.004.

[60] UNECA, Harnessing Traditional Governance in Southern Africa, 2007. http://hdl.handle.net/10855/14940 (accessed October 29, 2020).

[61] K. Baldwin, Why Vote with the Chief? Political Connections and Public Goods Provision in 
Zambia, Am. J. Pol. Sci. (2013). https://doi.org/10.1111/ajps.12023.

[62] S. Stritzke, P.A. Trotter, P. Twesigye, Towards responsive energy governance: Lessons from a holistic analysis of energy access in Uganda and Zambia, Energy Policy. 148 (2021) 111934. https://doi.org/10.1016/j.enpol.2020.111934.

[63] W. Kruger, S. Stritzke, P.A. Trotter, De-risking solar auctions in sub-Saharan Africa - A comparison of site selection strategies in South Africa and Zambia, Renew. Sustain. Energy Rev. 104 (2019). https://doi.org/10.1016/j.rser.2019.01.041.

[64] P. Samboko, M. Kabisa, G. Henley, Constraints to biofuel feedstock production expansion in Zambia, Dev. South. Afr. 36 (2019). https://doi.org/10.1080/0376835X.2018.1508988.

[65] P.A. Trotter, R. Maconachie, Populism, post-truth politics and the failure to deceive the public in Uganda' s energy debate, Energy Res. Soc. Sci. 43 (2018) 61-76. https://doi.org/10.1016/j.erss.2018.05.020.

[66] K.S. Rogge, K. Reichardt, Policy mixes for sustainability transitions: An extended concept and framework for analysis, Res. Policy. 45 (2016) 1620-1635. https://doi.org/10.1016/J.RESPOL.2016.04.004.

[67] K. Baldwin, P. Raffler, Traditional Leaders, Service Delivery, and Electoral Accountability, in: Decentralized Gov. Account., Cambridge University Press, 2019: pp. 61-90. https://doi.org/10.1017/9781108615594.004.

[68] F. Kemausuor, E. Ackom, Toward universal electrification in Ghana, Wiley Interdiscip. Rev. Energy Environ. (2017). https://doi.org/10.1002/wene.225.

[69] D.C. Moehler, N. Singh, Whose news do you trust? explaining trust in private versus public media in africa, Polit. Res. Q. 64 (2011) 276-292. https://doi.org/10.1177/1065912909349624. 